\title{
Communication and Police Organizations: The Case of Compstat ${ }^{1}$
}

\author{
Yusuf Yüksel
}

\begin{abstract}
Effective communication is suggested to be crucial for the success of organizations. In terms of police organizations, the hierarchical and bureaucratic structure, chain of command, centralized decision making, and cultural tendency to hide information that remain in many police organizations is believed to be the major obstacle in effective communication which, in turn, leads to coordination problems, distortion and unresponsiveness to environmental changes. Practical solutions in popular books remain in theory without organizing a system for effective communication.

This article analyzes communication aspect of a popular management model in the USA called Compstat which is suggested to help organizing a system for effective communication in police organizations. The data is collected through the interviews of 26 police officers and observation of Compstat meetings for 6 months in a large police organization (Newark Police Department) located in the USA. The findings suggest that Compstat model helped to overcome the communication problems rooted in bureaucracy and hierarchy of police organizations. However, there are still some problems in terms of disseminating information to frontline officers, the extent and quality of information sharing and expressing their thoughts freely in the regular Compstat meetings. Based on these findings, this article discusses deeply the contribution of this model for the communication problems in the police organizations and gives suggestions for practitioners.
\end{abstract}

Keywords: Police Organizations, Communication, Compstat, Compstat Meetings, Hierarchy, Bureaucracy.

\section{İletișim ve Polis Teșkilatı: Compstat Örnek Olayı}

\begin{abstract}
Öz
Etkili iletişim kurumların başarısında hayati bir role sahiptir. Polis teşkilatlarına bakıldığında ise, hiyerarşik ve bürokratik yapı, emir komuta zinciri, merkezi karar verme ve bilgi saklamaya yönelik yaygın kültürel eğilim etkili iletişimin önünde en önemli engel olarak görülmektedir. Bu durum ise koordinasyon ve iletişim sorunlarına ve çevresel değişimlere karşı duyarsızığa neden olmaktadır. Popüler kitaplarda yayınlanan pratik çözümler ise etkili iletişim için bir sistem kurulmadan teoride kalmaktadır.

Bu bağlamda, bu makalede, polis teşkilatlarında etkili bir iletişim sisteminin kurulmasına katkıda bulunduğu düşünülen, Amerika kaynaklıı popüler bir yönetim modeli olan Compstat'ın iletişim yönü analiz edilmektedir. Bu makalenin verileri, Amerika'da bulunan büyük bir polis teşkilatında (Newark Polis Teşkilatı) çalışan 26 polis ile yapılan mülakatlar ve Compstat toplantılarının 6 ay boyunca gözlemlenmesiyle toplanmıştır. Çalışmanın bulguları, Compstat modelinin polis teşkilatlarında iletişim sorunlarına neden olan hiyerarşik ve bürokratik yapı kaynaklı sorunların
\end{abstract}

1 Bu çalışma doktora tezinden faydalanılarak hazırlanmıştır.

2 Dr., Giresun III Emniyet Müdürlüğü. 
aşılmasına katkıda bulunduğunu göstermektedir. Ancak, bilginin sokak polislerine ulaşması, bilgi paylaşımının kalitesi ve oranı ve düşüncülerin özgürce ifade edilmesi noktasında sorunlar devam etmektedir. Bu bulgulardan yola çıkarak, bu makalede, bu modelin polis teşkilatlarındaki iletişim sorunlarına katkısı ve uygulayıcılara yönelik öneriler derinlemesine tartışılmaktadır.

Anahtar Kelimeler: Polis Teşkilatları, Iletişim, Compstat, Compstat Toplantıları, Hiyerarşi, Bürokrasi. 


\section{Introduction}

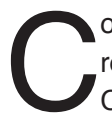

ommunication is the essence of organizations. It is the process by which meanings, relationships, and organizations are created and perpetuated (Putnam \& Krone, 2006). Communication also represents the means through which individuals in relationships, groups, organizations, and societies receive and transmit messages and create meanings to relate themselves to their environment and to one another (Ruben, 2005). As suggested by Ruben (2005: 294), through the communication mechanism, "joint activity is made possible; cooperation and conflict emerge and are addressed". Information is shared, and the system of leadership, power, identity, and culture are established and sustained within the organization. It is also used to command, inform, instruct, influence, persuade, integrate and relate things together (Thayer, 1986; 1988). Communication can be used effectively or ineffectively to keep the organization together, to inform organizational members, to facilitate and improve relationships, to decrease coordination problems, to create a vision shared by employees, to increase participation and satisfaction, to promote organizational change, innovation and a vision, and to implement daily practices (Lewis \& Seibold, 1998).

Different perspectives prioritize various roles of communication in an organization. While the positivist perspective and popular books on communication put more emphasize on information exchange in the organizations, system theory addresses the role of communication to relate the organization to its parts and the environment. Interpretive scholars focus on communication as a constitutive process and clarify the role of communication in terms of appropriateness, sense-making, and enactment of organizational practices (Orlikowski, 1992). Critical scholars drew attention to the relation of power and communication by placing more emphasis on communication's role in manipulating or dominating lower level employees and reproducing meanings which benefit some groups over others.

In spite of different conceptualizations and multiple roles ascribed to communication, the literature regarding communication in the police organizations view communication primarily as information exchange and focus on problems that can be eliminated through its effective use. The hierarchical and bureaucratic structure, chain of command, centralized decision making, and cultural tendency to hide information that remain in many police organizations is believed to be the major obstacle in effective communication which, in turn, leads to coordination problems, slowness, and distortion (Dantzker, 1999). Thus, in order to increase effectiveness in communication, clarity of messages, open, dynamic, timely, quality, sufficient, relevant, and productive communication, and effective listening have been proposed as practical solutions to police managers as well as the rationale for making structural shifts that will allow more and freer flow of information both horizontally and vertically among organizational members from different positions (Doerner \& Dantzker, 2001; Dawson, 2004).

However, these practical solutions remain in theory without organizing a system for effective communication in police organizations. Compstat is the most recent and popular management model among police organizations in the USA. Among many other aspects, this model is suggested to help organizing a system for effective communication and solve the communication problems in the police organizations.

Compstat emerged in 1994 in the New York Police Department (NYPD) as a new, complex, multifaceted system (Bratton \& Knobler, 1998). It was basically a response to the growing crime problem in large cities, especially crime-ridden urban areas in the USA during the 1980s and early 1990s. These problems increased the amount of criticism of the effectiveness of policing styles and police organizations, and thus led to the increase of change expectations (Newfield 
\& Jacobson, 2000). This specific model was initially developed as a means to collect timely and accurate information about daily crime patterns to initiate tactics and strategies, increase the flow of information and communication among precinct commanders, specialized units, and other departments, and ultimately increase performance and accountability (O'Connell \& Straub, 2007). Over time, "the initiative has been transformed into a more comprehensive form in its structure and promises, claiming to instigate the changes needed in police organizations and boasting the ability to reduce crime by making police organizations more responsive to management's direction and performance indicators" (Vito, Walsh \& Kunselman, 2005: 189).

Concerning the role that Compstat plays on communication in police organizations, the review of the literature focused most on its positive role. Based mostly on the case of the NYPD, it has been asserted that Compstat had certain impacts on information sharing and communication problems of the police organizations (Smith \& Bratton, 2001). Although this situation may be true for the NYPD, it is likely that implementing these kinds of management models do not necessarily result in their intended benefits in all police or public organizations. Thus, there is a need to question the success or failure in each organization that implemented these types of models without making assumptions as to their inherent success and the reasons behind its success and failure.

Based on this ground, an attempt will be made in this study to determine whether Compstat contributed solving the communication problems of another police organization in the USA (Newark Police Department-NPD) as intended. More specifically, the claims of Compstat to solve well known communication problems of police organizations will be analyzed based on a specific case. This specific case is likely to help other police organizations in Turkey as well as other countries. As such, the main question is:

- What is the role Compstat plays on communication in the NPD?

- What are the communication problems after Compstat in the NPD?

To answer these questions, in addition to opinions expressed by police officers in interviews, an analysis of communication practices employed during the Compstat meetings will be conducted. In the following parts, the literature regarding Compstat and its main components related to communication will be explained. After literature review, methodology of this article, main findings and discussion and implications parts will be shared.

\section{Compstat Paradigm}

\subsection{Definition of Compstat}

Compstat can be defined as a "goal-oriented strategic management process that builds upon police organizational paradigms of the past and blends them with the strategic management fundamentals of the business sector" (Walsh, 2001: 352). As many scholars have pointed out, although Compstat's description emphasizes crime statistics, crime data, and communication, it includes not only these factors but also a range of management principles in its structure to respond to problems. For instance, "the use of different policing styles (i.e., real time crime analysis, targeted crime interdiction, broken windows enforcement, directed patrol), adaptive culture, structural reorganization (i.e., empowerment, managerial accountability, teamwork, geographic decentralization), and a set of innovative strategies and motivational tools are counted in as a part of Compstat" (Silverman \& O'Connell, 1999: 130).

\subsection{Compstat Meetings}

The Compstat process has two main components: the gathering and analysis of statistical data in the form of weekly 'Compstat reports' and 'commander profile reports' and 'the Compstat 
meetings'. The Compstat meetings have been called to be the most visible part of the process. O'Connell and Straub (2007: 19) described the meetings as,

"an open forum in which to evaluate the success or lack of success regarding initiatives, strategies, and tactics that have been implemented. Discussions are direct and require every participant to be familiar with specific incidents, patterns, and trends and to articulate cogent action plans. Each participant is held accountable for achieving results regardless of the unit or bureau to which he/ she is assigned. The message is clear: poor performance must be corrected and good performance will be awarded".

Compstat meetings establish a measure of performance, accountability for achievement of the goals, and a sustainable process to ensure that the strategies have been carried out. These meetings also serve as a way to assess which strategies work and which ones do not (Buntin, 1999: 16). As suggested by Buntin (1999: 16), "innovative tactics that seemed to work quickly came to light and were immediately communicated to everyone attending; just as failed tactics were quickly exposed". These meetings are a major vehicle for officers to communicate, share best practices and failures, and motivate one another as well as a department-wide learning and accountability experience. They force precinct commanders to develop new strategies for fighting crime that will transform the way in which crime fighting is handled (Silverman, 1999). These meetings can be considered as a platform for facilitating the expression of implicit knowledge to others within the organization. Communication aspects of these meetings will be specifically discussed in the following sections.

\section{Police Organizations, Compstat and Communication}

As explained shortly, one of the main reasons for implementing Compstat at the NYPD was the lack of communication and information flow between headquarters, precincts, specialized units, and other departments. As Bratton and Knobler (1998) noted, precinct commanders had not communicated with officers for months and were even unaware of the crime rates within their precincts. In addition, precincts and specialized units in the same districts worked in isolation. "The centralization, rigid hierarchy, cultural tendencies to keep and conceal information and formalized communication mechanisms had limited the extent of informationsharing and interaction between NYPD's different units and departments" (Silverman, 1999: 129). The head of NYPD, William Bratton, believed that communication was essential for the effective coordination of crime fighting efforts and resources. For this reason, he outlined new mechanisms to open channels of communication and change the well-known behaviors of police officers to keep or hide information (O'Connell \& Straub, 2007).

The Compstat, specifically the regular meetings conducted in the Compstat's framework, was one of these mechanisms. The Compstat meetings are intended to provide grounds for information sharing and horizontal communication across all these organizational lines. Until these meetings were instituted, even precinct commanders at the NYPD had never be given the chance to speak directly to the commissioner. In theory, every participant was able to communicate openly with other participants, a type of communication that Bratton referred to as a 'seamless web'. If precinct commanders faced a resource problem during implementation of their crime solving strategy, they could speak directly to the responsible commander and request help in solving their issues (Henry, 2002). In this way, top-down, one-way bureaucratic communication was replaced with both two-way and horizontal communication. These meetings became a forum for the exchange of knowledge and facilitated the coordination of joint efforts and problem solving: "Issues that had previously taken weeks to resolve were quickly addressed since most necessary parties were assembled in the same room" (O'Connell \& Straub, 2007: 89). In short, it is claimed 
that communication and information sharing became part of the police culture in organizations.

Within this context, Compstat facilitates the use of information on a regular basis to increase coordination, collaboration, and development of effective strategies, and monitor the performance of different units. The regular collection and analysis of information through different mechanisms allows top executives to follow their planning and problem solving plans, prioritize and respond to gaps in these efforts, set and communicate new organizational goals accordingly, and monitor and evaluate the performance of the organization and organizational members in terms of the objectives they set. In addition, an individual's successful practices, skills, and performance are identified and used as a form of internal benchmarking that is eventually communicated and adapted to the organization (O'Connell \& Straub, 2007).

\section{Methodology}

\subsection{Research Setting}

In this article, a large police department, Newark Police Department (NPD), in the east coast of the USA was selected for an in-depth analysis of communication. This police department was selected as it is comparable to the NYPD in many senses. First and foremost, the NPD has employed the Compstat since 1997. In addition, its large size, crime ridden environment, problems in the organization, initiation of a number of innovative programs, reorganization of the department, and reduction in crime rates after the implementation of Compstat made this police department comparable to the NYPD and a good and interesting sample of study.

\subsection{Data Collection}

Data regarding on this issue was collected through in-depth interviews of police officers in different ranks and positions and observation of the Compstat meeting. The researcher conducted 26 interviews with members of the NPD. The basic sampling strategy was to reach a sample of individuals from diverse groups and varied functions within the organization. The interviews were arranged by a contact person who was assigned by the police director to assist with the study. There were a representative number of officers from a wide range of ranks and units. This enabled cross-checking of information in an effort to establish different views held concerning the communication aspect of the Compstat.

Observation was another data collection method used for this study. The main setting for observations was the Compstat meetings. The researcher attended nine meetings in 6 months and made observation approximately 18 hours. These meetings, as the most visible component of Compstat, presented a unique context in which to examine certain practices and conversations conducted in the scope of Compstat. They also allowed to researcher to understand how Compstat contributed communication in the NPD.

\subsection{Data Analysis}

The data obtained from the interviews and observation was used for the analysis and interpretation of the communication in this specific organization. The research took an inductive approach to examining the present phenomenon, insofar as the "categories emerge out of the examination of the data ... without firm preconceptions dictating relevance in concepts and hypotheses beforehand" (Walker, 1985: 58). The overall data analysis process can be considered in terms of two interrelated concepts: analysis and interpretation.

Specifically, the constant comparative method was used for analysis and interpretation. In fact, this method appears to be particularly useful in coding a large amount of texts, forming categories, establishing the conceptual boundaries of the categories, assigning the segments to 
categories, and summarizing (Strauss \& Corbin, 1998). All interview statements and field notes from Compstat meetings were logged into the computer for the analysis and interpretation of data.

The analysis process involved three stages: 'open coding, axial coding, and selective coding'. Open coding can be considered a form of content analysis where the data are read, coded, and categorized into themes on the basis of 'look-alike' characteristics rather than predetermined categories. The purpose is to "group similar events, happenings, and objects under a common heading or classification" (Strauss and Corbin, 1998: 103). Within this iterative process, a total of about 141 codes were generated. This process ended by classifying 141 codes under the 14 broader categories. The next step, axial coding, is "the process of relating categories to their subcategories and linking categories at the level of properties and dimensions" (Strauss and Corbin, 1998: 142). During axial coding, these categories were reviewed and re-sorted in order to relate them to subcategories, linkages, and relationships that have greater explanatory power to answer research questions. The final step is selective coding, in which core categories were selected and systematically integrated to narrate what is happening, form general explanations, generate a larger theoretical stance, and make knowledge claims about the organization studied.

\subsection{Limitations of the Study}

The most important limitation is the analysis of one organization at a certain period of time. This is about the generalizability of this study's findings for other police departments. It must be stated that this single case study has limitations in terms of statistical generalization. However, the tentative analytical generalization is still valid, appropriate and helpful for organizations that are willing to understand Compstat and the role of communication in this model (Yin, 2003).

Secondly, a similar limitation relates to the representativeness of study participants in this organization. The goal of this study was to conduct interviews with officers from different positions, units, and years of experience to generate a variety of perspectives, views, and opinions. In particular, the perspectives of former and current management, and former officers could improve this study, as they are freer to express their thoughts than current officers. However, this study did not fully tap the perspectives of upper level managers, former directors, and officers of this Police Department. Other than this limitation, there were representative numbers of officers (twenty six officers) from a wide range of ranks and units. This diversity helped to be heard the potentially valid concerns of officers on the ground, those who were generally disregarded in the management literature.

\section{Findings 4.1. Compstat and Communication}

One of the most important contributions of Compstat to the NPD is in the field of communication. Nearly all officers reported that Compstat enabled the NPD not only to collect daily and accurate information, but also to share this information with other officers and units. It is evident that Compstat allowed different sections, different commands, and different units to come together under a unified structure, without any structural barriers. Most of the study participants saw Compstat primarily as a tool to share information both within and between units. For instance, one officer noted,

"I think it is mostly about information sharing. What you are doing to control and prevent crime in your area. The most important thing is getting information out there and sharing with other parts of the department. Sometimes, whereas you may speak to your supervisor a lot, you don't speak to someone else in another department. Compstat gives you that kind of forum where you can just share information". 
On the same line of thought, police officers advocated that Compstat contributed better information sharing among precincts and special units like narcotics and gang. As stated by many officers, before Compstat, commanding officers did not have any communication with the other precincts or special units. They did not take any responsibility for crimes that happened in other precincts. However, the implementation of Compstat changed this manner by bringing commanders together regularly and compelling them to coordinate their efforts. This change was expressed by one officer as follows:

"The difference is in communication. Prior to this Compstat, there was not a lot of communication across precincts. Things were very specific and territorial. We had different segment of the department only worrying about their specific community. It was not taken into consideration that someone else's problems in another community would also affect their part, too. So, we were very territorial and there was not a lot of communication".

Another officer pointed out that the role of Compstat goes beyond information sharing as follows:

"The role that Compstat plays, it brings people together to brain-storm to identify problems, brainstorm to come up with the best alternative and solve the problem. Because you may find out, you may have alternatives, thorough talking, brain storming, we may have a better idea".

Many study participants referred to the large size of the NPD and the greater number of people through whom information must pass while explaining the function and inevitability of Compstat in the NPD. For instance, one commander spoke about disseminating and sharing information across departments:

\footnotetext{
"It becomes constant sharing of information across the border. And there is no secret that there was no barrier between either chief, director and with that commander. This was open forum. You as a commander of the third precincts would get this information and you knew what was going on in the department, across the department, across finance, across vehicles, across computers, across detention. You knew what was going on in the whole department. This is a necessity in such a large organization".
}

It is clear that most of the officers supported the contribution of Compstat to the communication.

\subsection{Compstat Meetings and Communication}

When talking about the positive role of Compstat in terms of communication, nearly all officers referred to the Compstat meetings. In other words, these meetings were suggested to be the most critical and ritualistic occasions for information sharing and bonding. Nearly all examples regarding information sharing were from these meetings. The following statement of one officer illustrated the common point of view of officers regarding Compstat meetings:

"In terms of its function, people come together to share information. Probably it is one of the most important factors of Compstat. Commanders, investigative units, a whole host of people come there. So, people can talk about their problems. "Listen up, we have a problem here, what do you think you can do to help me?" Without these meetings, we would not bring everyone in this room. Everyone is hearing the problems of other precinct commanders. They can say, you know what I have the same issue. Okay. You come together and discuss it. And give me a plan of action for how you are going to address this issue".

Compstat meetings provide a platform to present and share information. Officers in the NPD clearly benefited from this platform. A large amount of information in the form of crime analysis and crime patterns was presented in these meetings by commanders. Commanders were also required to explain how they deployed their resources and their plan to respond to emerging 
crime problems in the presence of other officers.

The observation of the meetings confirmed the critical role of these meetings in terms of communication. Every moment of these meetings can be evaluated in terms of information sharing, correcting problems in timely manner, and sharing best practices. For instance, during a discussion of wanted criminals, it was understood that there was a problem of updating and disseminating of wanted posters. With the order of the police director, one captain took responsibility for putting together packages for wanted individuals, to be disseminated to all precincts. Similarly, in one meeting, commanding officers talked about how to accurately check pawn shops. The following statement of one ranked officer shows how these meetings helped to get things done:

\footnotetext{
"You bring people from all departments. I mean, you have people from the support services bureau, so if you have a command that has a particular problem with vehicles, radio, or something, because the highest rank of people is sitting in the meeting, things get done. Let's resolve this problem and do everything we can do to make sure that this precinct commander can be successful".
}

As shown, the Compstat meetings brought together mostly middle and upper level officers from different units and enabled them to talk and hear what was going on in other units. This, in turn, enabled them to make a comparison, benefit from the experience of other units, and solve problems in a timely manner.

As observed in six months, the meetings clearly made officers talk about their crime problems, management problems, and solutions to the problems, and enabled them to coordinate efforts with other units. The following questions of the deputy chief in the meeting captured the contribution of Compstat to the coordination problems among different units:

\footnotetext{
"How many times in these 28 days did a narcotic lieutenant come to your office in the second precinct? Did you have a conversation about your burglary problem in top priority narcotics locations?"
}

These statements and dialogues in the meetings confirm the contribution of Compstat to decreasing communication and coordination problems. In short, these regular Compstat meetings with its form and content helped to overcome the problems rooted in bureaucracy and hierarchy of police organizations that leads to lack of communication within and with different units and unresponsiveness to environmental changes. However, this is not to say that Compstat completely ignores and change bureaucratic structure and hierarchy. Rather, Compstat seems to be injected into the system without changing the other components of bureaucratic structure in the NPD. In addition to the Compstat meetings, the regular roll call meetings and crime information centers in each precinct, where crime maps, wanted people, and crime statistics were displayed urged information sharing within each precinct.

This is not to say that there were no problems regarding information sharing. Although Compstat was said to be a good tool to gather, use, and share information, and coordinate joint efforts, the effectiveness of the initiative was heavily dependent on certain mechanisms that ensure effective use of this information and two-way communication flowing upward and downward throughout the organization. However, there were a range of problems and limitations reported by the study participants and observed in the meetings.

\subsection{Problems in Communication}

One of the most cited problem is the gap between upper, mid and street level officers. A number of managers expressed the critical role of getting information out and helping front line officers to understand what is expected from them and the implications of Compstat for their daily practices. 
This is highly critical point because all plans and tactics should be reflected on the street level, where the real fight with crime occurs. For instance, a commander spoke about why this is important:

"To me, Compstat is all about getting information to the officer in the field so he can be more productive and we can reduce crime. That is the bottom-line to me. I am a captain; I don't go out and fight crime every day. I know all about what is going on in my precincts, but that does not help the officers who are sitting in a police car at midnight tour, if I don't get the information out that I know. So, we need to explain to the cops in the field why we need to do certain things. It is all communication".

In fact, there are certain mechanisms in the NPD to inform frontline officers about these issues, such as crime control centers and roll call meetings. A commander confirmed the use of these mechanisms for this purpose:

"We do have methods in place now, like putting crime maps and bulletins out, putting crime information out for the officers. We also use roll calls getting information out. We put out information about burglars, burglaries of this week, the 28 day period of Compstat. So, they know that there are patterns out there, crime patterns, and they know what is going on, what to look for".

These mechanisms provide a base from which to disseminate information to front line officers who are doing the job on the ground. However, it was not clear to what extent street level officers benefitted from these mechanisms that were put into practice with Compstat. The data gathered in this study pointed out that there was still a lack of information among front line officers regarding their responsibilities in this process and implications of Compstat for their daily practices. It was stated that the meaning and implications of the information analyzed were lost between the upper managers and front line officers. Consider the following comment provided by a commander who regularly attended Compstat meetings:

"One of the things we try to do and probably we can improve on is getting information out to our police officers a little bit better. But it depends on the sergeants and line supervisors, and mid managers. If they are not good at what they do, if they are not taking significant interest in what is going on around them, then, they don't give the police officers information that they need to be better at what they do".

As shown, to be useful, supervisors at different ranks need to make sure that the information was swiftly disseminated upward and downward throughout the organization, and make sure that they were aware of what was expected from them, specifically, the underlying patterns in the data, and the logic behind the strategies and deployment efforts.

In the same line of thought, in the Compstat meetings, the police director repeatedly asked commanding officers to get briefings and tell officers in their units how and what is supposed to be done based on the crime analysis and patterns. Another suggestion of some commanders to overcome this problem was to bring the front line officers to the meetings at different times, to show how Compstat works and why commanders ask for certain things. For instance, one commander said,

"You have to make them understand what we need, even by taking some of them to Compstat. They will see how the process works and they will get it".

However, as confirmed by the observation of the meetings, this was not a common practice in the NPD. Nearly all participants of these meetings were ranked officers. While explaining the reason for this, one ranked officer noted that, 
"In fact, the director asked us to bring people. But, I guess we did not want to bring them to Compstat where we were yelled at. We don't want them see we are yelled at in the meetings. I believe we should do that. That was our fault".

This is not to say that there was not any change on the street level. Even if there were problems passing information and tactics devised in Compstat meetings, there was a real reflection of Compstat on the street level. As wisely captured by a commander, even if they were not aware of all process and implications of Compstat on their daily routines and the true spirit behind this initiative, Compstat certainly influenced their work on the street level:

"They are not involved in the Compstat process itself, but they are involved in this fighting crime. They don't even know what is going on, they don't have a bigger sense of the organization yet, and a lot of them are relatively new. They don't develop plans for the work. They come there, put their time in and go home. They may not even realize why they are doing certain jobs, but it is also part of Compstat. To them, they are fighting crime. You put them in an area and they fight crime. What do you want me to do; record check people, arrest people, give more summonses, and give more summonses. They do that because that is for what they are paid to. To them, it is not Compstat, it is police work".

In addition to limitations in the information flow, there were problems with the quality of information sharing, hierarchical and cultural pressures to explain information freely, and adopting this information to resource deployment and police tactics on the ground. As reported in the following statement, officers were not comfortable enough to discuss their problems freely for several reasons:

"People become exclusive. They don't really want to say what their issues are. They talk about the analysis of crime in terms of time of day, day of week because it is just basic human nature to know I do enough. Is that enough for that person who is asking me the questions? Is that going to satisfy him? If he is not satisfied, he is going to make me work on it. Is he going to make fun of it? Is he going to transfer me? So, when you sit in a room with your peers, there are a lot of people, a lot of pressure. People really don't want to share their information. Don't say it because everyone is aware of the issue, they have no other choice. But, if there is something that they can keep to themselves without saying it in open form, I think they will. That is probably one of the negatives of Compstat, because fear of embarrassment, fear of being ridiculed, fear of giving me more work. Wait a minute, I work ten hours in a day, if I knew about this issue, I have to work 12 hours a day. So, whoever says that people are 100 percent open, I don't think so. The percentage of openness I don't know. I speak on behalf of myself. I am on a different side of the table now".

Another problem was that Compstat injected a heavy dose of information regarding crime rates, trends, and patters that have implications for the daily routines of frontline officers. To be useful, this information should be thoroughly reviewed and digested at different levels of the organization. However, this is a difficult task, especially in such a big organization where there are a range of officers with varying commitments to the job. As explained by a commander,

"If you work in a big organization, people have varying commitments to the job. There are some people who care about what they do, fully committed. There are some others to get the pay check. The difficult part is to make sure that even the least interested police officers know exactly what is going on in their commands. It depends on how much effort they put in reading the information and reviewing it. We give the information to our commanders, lieutenants, and sergeant every week, when the Compstat package is prepared. They can get that information and review it. They should have the big picture; at least they should have the knowledge of what is happening on their shift so they can better direct the personnel". 
It seems reasonable to suggest that some officers would struggle to digest and respond to this amount of data that is produced on a daily basis.

To summarize, in spite of certain limitations, the problems regarding information sharing rooted in the hierarchical, divisional structure of police organizations, and the historically suggested cultural barriers to sharing information seemed to be overcome to a large extent in the Compstat era. The mechanism of Compstat (i.e., Compstat meetings, crime information centers, roll call meetings) inevitably supported information sharing at different levels. And, all these mechanisms seemed to be accepted and internalized by officers for some time after the implementation of the initiative. The basic mechanism used for information sharing, their function, and limitations are shown in the following table.

Table 1. Communication as Information Exchange

\begin{tabular}{|l|}
\hline \multicolumn{1}{|c|}{ MECHANISMS USED FOR INFORMATION EXCHANGE } \\
\hline Compstat Meetings / Roll Calls / Crime Information Centers / Written Documents /Informal Discussions \\
\hline - Collecting different units under a unified structure \\
- Sharing information between precints, different units, special units without any barriers \\
- Urging different units to coordinate their effort \\
- Correcting problems in a timely manner \\
- Brainstorming, sharing best practices, getting things done in timely manner \\
- Sharing daily crime trends and priorities, getting a proactive policing style \\
\hline Thotion of open communication and being on the same page \\
\hline - The level of disseminating information to frontline officers \\
- The level of understanding Compstat and the implications of Compstat for daily practices \\
- The extent and quality of information sharing in the meetings \\
- The extent of change on the daily practices of frontline officers \\
- Historachical and cultural pressures to explain information freely in meetings \\
\hline
\end{tabular}

\section{Discussion}

Compstat is suggested to help the NPD to overcome communication problems. Without exception, Compstat is intended to provide an opportunity to bring together different units and precincts to talk about their problems, to share information and best practices, and to coordinate their efforts 
and resources. Not only Compstat meetings but also roll call meetings conducted before each shift in each precinct became inseparable parts of this initiative. In addition, the distribution of crime maps and statistics to officers on duty, and the display of crime analysis and patterns on crime information centers in each precinct supported this system. As such, Compstat clearly implemented new procedures and introduced new communication links in and between different units and precincts. This initiative was even called as a form of information-led policing. This system was said to bring a unified, organization wide perspective to the fight against crime.

In addition, information technologies (i.e., computers, crime maps, GPS systems) played a central role in the implementation of Compstat, the improvement of communication, and the transformation of policing in general. They allowed organizations to operate across time and space through flexible and decentralized structures. In particular, information technologies were argued to play a central role in enabling coordination of people and tasks, and the information sharing aspect of Compstat. In that sense, technological improvements, computers, and crime mapping were believed to play a key role as the visible face of the Compstat, and also increased its magnetism.

The Compstat meetings, roll calls, and all types of written documents were suggested to be part of communication. Compstat brought together all units and upper echelon together under a unified structure without any barrier to talk and share information about their precincts and problems. This structure was certainly helpful in this large organization, where there were many officers through whom information must pass. This point was repeatedly asserted as 'being on the same page', and 'open communication'. The critical point to be emphasized is this open forum of communication decreased the likelihood that communication will be transformed or distorted between ranks and units.

In addition to information exchange, coordination and collaboration were two additional points that was used to define the role of Compstat regarding communication. It was believed that the Compstat initiative, with its principals and practices, increased the level of coordination and collaboration. The focus on bringing in different units and asking relentlessly for joint efforts reinforced coordination and collaboration in this organization. In particular, the availability of different units as well as upper echelon in these meetings made it possible to resolve problems and get things done in coordination. If there was a problem in the coordination efforts, the upper echelon wanted related units come together after the meeting and put together a plan within a certain time frame. There were also examples of coordination with external agencies, such as courts, the municipality, and parole office. All these points were believed to bring promptness, flexibility, and effectiveness in the deployment of resources, responding to crime and get things done timely and appropriately.

The contribution of Compstat to communication was evident, but this is not to say that there were not any problems in practice. There were a range of problems and limitations in the collection, use, sharing of information, and coordination that were reported by the study participants and observed in the meetings. These limitations were thought to be related to personal wrongdoings, cultural habits, resource constraints, organizational size, and managerial style.

The information produced, put into documents in terms of Compstat, and talked about in the Compstat meetings must be swiftly disseminated upward and downward throughout the organization. As suggested in the article of Dabney (2010:27) and confirmed in this study, "to be useful, the underlying patterns in the data, the logic behind the strategies and deployment efforts, and the assessment must be thoroughly digested at all levels of the organization. This sort of design is heavily dependent on efficient and effective lines of two-way communication 
flowing upward and downward throughout the organization". The data in this study suggested that the downward moving strategic messages often got lost between the Compstat meeting and the ground-level deployment. Even if front line officers put into practice some of the strategies and tactics, they were away from understanding the logic behind the strategies and deployment efforts.

The possible strategies for overcoming this problem by bringing front line officers to the meetings in a specific order, or providing the active contribution of field supervisors to the meetings as they were in a situation to convey the messages from the ground up in the organization did not work as expected. Mid-level commanders were not willing to bring the front line officers to the meetings as they did not want to be interrogated in front of their subordinates. It is problematic to expect these street level supervisors to convey the strategic messages or inspire front line officers in the roll call meetings, which were key for the success of the initiative. However, this is not to say that there was not any change on the street level. Even if front line officers were not aware of all process and implications of Compstat on their daily routines and the true spirit behind this initiative, Compstat certainly influenced their work on the street level by the assignments directed to them.

Similarly, Compstat injected a heavy dose of information regarding crime rates, trends, and patterns that have implications for the daily routines of frontline officers. To be useful, this information should be thoroughly reviewed and digested at different levels of the organization (Dabney, 2010). For this reason, two-ways of communication and systematic communication strategies were needed to convey all the strategies and tactics and ensure that officers internalize them. However, there was not any regulation or systematic effort to do this other than personal initiatives of each commander.

In addition to limitations in the information flow, specifically to the lower level officers, the extent of information sharing seemed to have been limited even during the meetings. There were problems with the quality of information sharing, hierarchical and cultural pressures to explain information freely, and adopting this information to resource deployment and police tactics on the ground. Officers did not benefit extensively from this platform, physical togetherness, and being in front of an authority that enable them to talk and possibly solve their problems immediately. The communication skills of officers, the climate of the relationship and setting, the history of these meetings, and differences in values, norms, and attitudes of the people play a role in the level and quality of information sharing. The police director and deputy chief asked questions and commanders responded to them in a way that they think the upper managers expected of them and share their information and problems in a limited manner.

Officers were not comfortable enough to discuss their problems freely for several reasons: The design of meetings (i.e., number of participants, meeting room), the design of communication (i.e., question-answer form), the history of police organization (i.e., intimidation and humiliation in the early forms of meetings), the cultural values and personal attitudes of officers in organization (i.e. avoiding extra work, defensive culture), and organizational constraints in terms of resources.

There were also limitations in the extent of coordination among different units to deploy resources synchronically. There were many examples from the meetings where the police director and deputy chief expressed displeasure with the coordination and asked commanders to meet after Compstat meeting to coordinate their efforts. There were statements in minutes of meetings such as, "Captain A and B need to coordinate and make sure that there is a joint effort to supply the needs at emergency." There were more examples of these kinds of statements that prove lack of coordination between different units in the NPD. 
Another important communication related problem was the ritualistic nature of communication practices in the meetings. Through communicating with others in the organization, officers learn to accept the values and norms of the meetings and construct a self-identity that is appropriate to the rules they play by. In other words, communication leads to convergence in the invisible rules and practices and enables the development of patterned ways of communicating, each with their own meanings. In this setting, it was evident that routines became a big part of organizational activity and the same type of information was produced and shared in the meetings. The problem was how these structured patterns of communication and these invisible rules and regulations contribute to a climate of innovation, creativity, and real participation. The data in this study suggested that it was rare to see creativity, innovation, or real participation of officers in the meetings. It seemed like there was a comfort zone between middle level and upper level officers in terms of information shared in the meetings. Specifically, officers tried to stay within a range of options accepted by the upper echelon. Many officers stated that they sometimes say what was expected rather than what was needed as they want to avoid extra work, taking risks, and criticism or humiliation in front of their peers and the upper echelon. The upper echelon intervened when the information level and responding strategies were perceived to be inadequate. On one hand, this situation inevitably brought ritualism to the communication practices and decreased the quality of information as well as creativity and innovation in Compstat. On the other hand, it decreased uncertainty and brought practicality and effectiveness into the communication practices

\subsection{Suggestions}

This design, -structure and setting- of communication often influence the contribution of other participants to the process, climate of real participation, innovation, and organizational learning. It was observed in the Compstat meetings that the same group of people talked and talked again. In particular, line level supervisors (sergeants) who were critical to conveying messages to the front line officers seemed to be alienated in the meetings. The number of participants, their seating position and the room design, and the manner of questions could be redesigned to increase the contribution of all officers. In this sense, the number of participants and their role in these kinds of gatherings need to be redefined; and their active contributions also need to be encouraged to spur brain storming and promote a learning environment. This new form of design, which is intended to encourage interaction, can be tested and refined to achieve the desired goals.

At this point, the upper echelon's role is also critical in making organizational members feel comfortable expressing their opinion freely without any kind of retribution. If fear of wrong- doing and humiliation, mistrust, and hierarchical control can be kept at a reasonable level, the trust and comfort levels will certainly increase which is key for building a genuine dialogue instead of talking considering the expectations of upper echelon. A meaningful dialogue permits individuals to revise the way they see something and allows for the relational development required for organizational learning, creativity, and innovation.

Involvement of different officers to the Compstat meetings would increase the level of understanding and information regarding what was expected and why. Organizational members at all levels of an organization affected by change should be involved in certain practices at certain degrees, based on their position, rank, and changing responsibilities associated with the change initiative. The lack of involvement and awareness of how change initiatives influence or should influence the daily practices may lead to the lack of change in the particular behavior and daily practices. Given this point, each organization needs to consider involving its members in certain mechanisms to make them aware of new initiatives and their role in this initiative. As such, the goals and strategies formulated in Compstat meetings would be better communicated and reflected on the ground rather than diluted or diverted as they make their way down to the street level. 


\section{Conclusion}

The success of Compstat and specific initiatives like Compstat certainly requires an understanding of the nature of the communication process. The findings point to the important role of Compstat in communication practices of the officers in the NPD. Although the contribution of the Compstat to the communication was evident, there is still need for improving communication in the NPD.

The Turkish National Police (TNP) faces to similar problems such as increased crime rates, strict bureaucracy, and lack of communication, which Compstat claims to solve. The model has a high potential to address some of these operational and managerial problems of the Turkish National Police including communication. This study shed light on the story of Compstat in the NPD, but it can be certainly adapted to the Turkish National Police. However, there are potential difficulties for the implementation of this model in Turkey in terms of the differences between the USA and Turkey in the police structure, culture, technological infrastructure, and policing approaches. Only after we take into account these difficulties and assess carefully the modifications needed in the Compstat model and TNP, it is more likely to help us to overcome the problems of the TNP.

For this reason, future research should make a comparison of Turkey and USA in terms of their structure, culture, technological infrastructure, and policing approaches and provide a perspective for practitioners who are willing to adapt this kind of models. This study elaborated the possible contribution of Compstat model to the communication problems in the police organizations. Future research should also investigate and capture different managerial and operational aspects of this model and its implications for daily practices in any police organization.

\section{References}

Bratton, W., \& Knobler, P. (1998). Turnaround: How America's top cop reversed the crime epidemic. New York: Random House.

Buntin, J. (1999). Assertive policing, plummeting crime: The NYPD takes on crime in New York City. John F. Kennedy School of Government. Cambridge: MA.

Dantzker, M. L. (1999). Police organization and management: Yesterday, today, and tomorrow. Boston: Butterworth-Heinemann.

Dawson, P. (2004). Managing change. In D. Tourish \& O. Hargie (Eds.), Key issues in organizational communication (pp. 60-73). New York: Routledge.

Doerner, W. G., \& Dantzker, M. L. (2000). Contemporary police organization and management: Issues and trends. Boston: Butterworth-Heinemann.

Henry, V.E. (2002). The Compstat paradigm. New York: Looseleaf Law Publications Inc.

Kelling, G.L., \& Sousa, W.H. (2001). Do police matter? An analysis of the impact of New York City's police reforms. New York: Center for Civic Innovation at the Manhattan Institute.

Lewis, L. K. \& Seibold, D. R. (1998). Reconceptualizing organizational change implementation as a communication problem: A review of literature and research agenda. Communication Yearbook, 21, 92-151.

Newfield, J., \& Jacobson, M. (2000). An interview with William Bratton. Retrieved March 27, 2007, from Academic Search Premier Database.

O’Connell P. E. \& Straub F. (2007). Performance-Based management for police organizations. Illinois: Waveland Press, Inc.

Orlikowski, W. J. (1992). CASE tools as organizational change: Investigating incremental and radical changes 
in systems development. MIS Quarterly, 17, 309-340.

Putnam, L. L., \& Krone, K. J. (2006). Editors' introduction. In L. L. Putnam \& K. J. Krone (Eds.), Organizational communication (pp. xxiii - xliii). Thousand Oaks, CA: Sage.

Ruben, B. D. (2005). Excellence in Higher Education: A Guide to Assessment, Planning and Improvement in Colleges and Universities. Washington, DC: National Association of College and University Business Officers.

Silverman, E. B. (1999). NYPD battles crime: Innovative Strategies in policing. Boston: Northeastern University Press.

Smith, D. C., \& Bratton, W. J. (2001). Performance management in New York City: COMPSTAT and the Revolution in Police Management. In D. Forsythe (Ed.), Quicker, better, cheaper? Managing performance in American Government (pp. 452-483). New York: Rockefeller Institute.

Strauss, A. L., \& Corbin, J. M. (1998). Basics of Qualitative Research: Techniques and Procedures for Developing Grounded theory (2nd ed.). Thousand Oaks, CA: Sage.

Thayer, L. (1986). Communication and communication systems: In Organization, Management, and İnterpersonal relations. Lanham: University Press of America.

Thayer, L. (1988). On communication: Essays in understanding. New Jersey: Ablex Publishing Corporation.

Vito, G. F., Walsh, W. F., \& Kunselman, J. (2005). Compstat: The Manager's Perspective. International Journal of Police Science and Management, 7, 187-196.

Walker, R. (Ed). (1985). Applied Qualitative Research. Aldershot, UK: Gower.

Yin, R. K. (2003). Case Study Research Design and Methods (3d ed.). Thousand Oaks, CA: Sage Publications. 